\title{
Making sense of sensemaking: conceptualising how child and family social workers process assessment information
}

\begin{abstract}
This article offers a new conceptualisation of sensemaking in social work assessment. During assessment, social workers are required to make sense of a wide range of information. This may include written reports, behavioural cues, verbal, sensory and emotional data. In this article, the term 'sensemaking' is used to refer to the processes through which social workers gather, select and interpret this varied, and often incomplete, information during assessment. Sensemaking is defined as a psychosocial process which precedes and underpins professional judgement and decision-making. While there has been interest in how social workers assess risk to children, the sensemaking process that occurs before a decision is made has received less attention, and sensemaking lacks a clear definition. Drawing on existing research on assessment and theoretical literature from the fields of psychology and organisational studies, this article offers a view of sensemaking through three lenses: sensemaking as intuitive process, sensemaking as social storytelling and sensemaking as an emotionally-informed process. Drawing together key features from these three perspectives, we advance six propositions about sensemaking in child and family assessment: 1) sensemaking is a process of formulation; 2) sensemaking involves movement between conscious and non-conscious processes; 3 ) sensemaking can be developed through experience and learning through reflection; 4) sensemaking is inseparable from the environment in which it takes place 5) sensemaking is a dialogic process; 6 ) sensemaking is an emotionally-informed as well as cognitive process. The article concludes with the implications of this conceptualisation of sensemaking for assessment in child and family social work.
\end{abstract}

\section{Introduction}

Reviews of high-profile child deaths in the UK (Laming, 2003, 2009) have focused on how social workers make judgements about risk to children, and the day-to-day contexts that shape their decisions (Munro, 1999). Child and family social workers are tasked with making sense of incomplete, often contradictory information during assessment. How social workers process, interpret and determine the significance of information at the early stage of assessment is key for the future trajectory of the case. The social worker's first impressions, based on an initial referral (Munro, 1999) or formed during an encounter with the family, are notoriously pervasive (Munro, 1995), shaping subsequent judgements made in relation to the family. Where these initial impressions are inaccurate, children can be left at risk. Research has focused on early assessment, including the modes of reasoning and rules of thumb employed by social workers at this crucial stage (e.g. Kirkman and Melrose, 2014; Saltiel, 2016; Whittaker, 2018; Saltiel and Lakey, 2019). Research has highlighted the risks of error in early assessment, where shortcuts in the reasoning process can lead to predictable biases (Munro, 1999; Broadhurst et al, 2010; Hackett and Taylor, 2014).

This article conceptualises the process of sensemaking - the everyday, situated ways in which social workers identify, select and attribute meaning to assessment information before arriving at a judgement. Although the phenomenon of sensemaking has been explored within the fields of psychology (Klein et al, 2007) and organisational studies (Weick et al, 2005), it has received less attention in social work literature. While small number of studies which have explicitly examined sensemaking (Collings and Davies, 2008; Helm, 2013; Helm, 2017; Cook, 2017; Avby, 2015), attempts to conceptualise it have been provisional and tentative, with sensemaking identified as a process that precedes the formulation of a judgement and decision-making (Platt and Turney, 2014). This article provides a conceptualisation of sensemaking using three lenses: intuition, social storytelling, and emotion. 
We define sensemaking as a psychosocial process which combines intrapersonal, interpersonal, and social processes. Understanding the processes involved in sensemaking is important for the promotion of effective professional judgement. We argue that recognising the influences on sensemaking can help social workers to subject their reasoning processes to scrutiny and, potentially, to avoid some of the 'predictable biases' (Munro, 2008:6) in their assessment of children and families.

\section{Defining sensemaking}

When carrying out an assessment, social workers must make judgements about the child and family's situation, needs and level of risk. These judgements then inform the basis of a decision - the selection of a particular intervention or course of action. However, before arriving at a judgement or making a decision, the social worker must first identify, select and interpret a wide variety of data. This data could consist of a written referral from another agency, a verbal report from a concerned neighbour, the parents' body language or the child's behaviour during a home visit. Processing this information is likely to involve making sense of social encounters (such as interaction with children) and noticing salient cues or patterns in the information received. Thus sensemaking in early assessment is a nuanced and contextual process, rather than a dispassionate weighing up of 'facts'. For instance, sensemaking might begin with noticing something during a visit, or experiencing a 'gut feeling' or 'niggle' that requires further investigation (Cook, 2017). Sensemaking therefore precedes the forming of a judgement and the taking of a decision; it is the process through which social workers interact with the available data to formulate a judgement (Platt and Turney, 2014).

Sensemaking is an interpretative activity. When meeting families, social workers must interpret emotional and behavioural information (Saltiel and Lakey, 2019). For instance, the social worker may need to 'read' the body language of a child during a visit to determine whether they are fearful of their parent, reluctant to share information or merely shy and hesitant as a result of the social worker's visit. As well as reading body language and other social cues, sensemaking involves absorbing and interpreting sensory and contextual information. As de Montigny (2018: 463) states:

In the mundane work of observation and dialogue ...the social worker shares the sights, scents, and tastes of life that transcend narrative and talk to reveal the realities of a client's life.

Sensemaking is the process through which social workers attribute meaning and significance to what they see, hear and feel in their work with families (Cook, 2016). In the course of undertaking an assessment, it is what enables the social worker to move from their encounters with the data, such as observations from visits, views of other professionals, the case history, to a judgement about risk of harm. Making sense of this information is a complex process, involving the social worker's emotional responses, existing professional knowledge and accumulated life experience (Saltiel and Lakey, 2019). This article offers a conceptualisation of the processes involved in sensemaking using three theoretical lenses, which are explored in turn.

In order to identify relevant theoretical and empirical research on sensemaking, an initial literature search was conducted via the following academic database: Taylor and Francis, EbscoHost, Sage Journals, Cambridge Journals, Oxford Journals and Wiley Online. A series of combined search terms were used, which included 'sensemaking' 'sense-making' 'social work' and 'assessment'. The literature on sensemaking in social work is often embedded within articles as a secondary topic. This literature review therefore involved considerable hand searching alongside the use of articles known to the authors. For these reasons, the literature identified in this article is not claimed to be exhaustive. Given the limited number of social work articles containing 'sensemaking' as a main focus, the inclusion criteria was broadened to include both theoretical and empirical literature from the fields of psychology, narrative and organisational studies. The material from other disciplines has been used 
to frame the limited empirical research on sensemaking in social work, and to conceptualise sensemaking in social work.

\section{Sensemaking as an intuitive process}

Social workers are often tasked with making rapid sense of complex situations where a child is perceived to be at risk (van de Luitgaarden, 2009). The concept of intuition is helpful for understanding how social workers make sense of referrals to Children's Services in the context of limited time and the need for rapid appraisal and action. Intuition is a sense of knowing without being able to articulate how we know (Topolinski, 2011). Within the psychological literature it is defined in contrast to analytic reasoning. Intuitive reasoning is quick, automatic and unconscious, while analytic reasoning is slow, deliberate and effortful (Kahneman and Klein, 2009). When making sense of information during assessment, social workers need to be able to rapidly identify indicators of risk and gauge the level of response required. It has been suggested that the complexity of the kinds of social situations that social workers need to interpret is not suited to the computational nature of analytic reasoning (Taylor, 2017) and is instead reliant on a identifying patterns within complexity high (such as the thousands of cues present during social interactions in order to form a judgement (Saltiel and Lakey, 2019).

Three schools of thought have developed around the nature and reliability of intuitive reasoning: the heuristics and biases tradition (HB), fast and frugal heuristics (FFH) and naturalistic decision-making (NDM) (see Kahneman and Klein, 2009 for an exposition of the similarities and differences between the traditions). Within the HB and FFH traditions, heuristics are defined as 'rules of thumb' which enable certain shortcuts to be taken in the decision-making process where the complexity of the situation precludes a fully rational, computational analysis (Taylor, 2017). Research suggests that such unofficial 'rules of thumb' are used by social workers to make sense of assessment information. For instance, research has identified how parental 'openness', contrition and willingness to discuss concerns are used by social workers to gauge risk to the child (Buckley, 1999; Cook, 2016), and that social workers use prior cases to gauge the 'severity' of risk in a current case (Kirkman and Melrose, 2014). Within the HB tradition, Kahneman and Fredrick (2002) discuss the interplay between System 1 (intuitive) and System 2 (analytic) reasoning. System 2 reasoning can act as a check against quicker System 1 reasoning, enabling intuitive judgements to be scrutinised and revised (Kahneman and Frederick, 2002) reducing the risk of bias.

The interplay between System 1 and System 2 thinking is known as the dual process model (Whittaker, 2018). Slower, more deliberate System 2 reasoning can become System 1 thinking through experience and repetition. In this way, social workers may become more proficient at making sense of cases as they become more experienced in assessing risk. Heuristic shortcuts used by social workers can also be based on practice knowledge and wisdom specific to the complex psychosocial environment in which social work takes place (Taylor, 2017).

Klein (2015), writing in the NDM tradition, views intuition as a form of pattern-recognition. His recognition-primed decision-making model (RPD) asserts that expert decision-makers can quickly and accurately respond to situational cues to enable effective judgements (Klein, 2015). For Klein, expertise is developed through repeated exposure to decision-making environments that contain predictable cues; experts have a broad repertoire of patterns to intuitively call to mind to reach effective judgements without the need for deliberate, conscious analysis (Klein, 2015). This suggests that repeated experiences of assessing children and families may sensitise social workers to recognise patterns indicative of risk, allowing them to intuitively identify risk in subsequent cases.

Empirical research shows that experienced social workers demonstrate greater skill in patternrecognition than less experienced workers (Whittaker, 2018). Experienced workers are also 
comparatively more skilled at focusing on a smaller range of relevant cues when faced with large quantities of complex information (Whittaker, 2018). This suggests that social workers are capable of developing expertise in forming intuitive judgements and are able to use experience-based heuristics to simplify complex information when undertaking assessments of children (Whittaker, 2018).

Sensemaking has two functions when understood in relation to heuristics and RPD. Firstly, the way initial judgements are formed - whether through RPD or the use of heuristics - can be seen as a process of intuitive sensemaking. Sensemaking is the process through which significance is attached to the many and varied pieces of information and situational cues that enable a pattern-match (Klein, 2015) or use of a relevant heuristic shortcut (Taylor, 2017). Secondly, the dual process model suggests that heuristics can be checked and revised through analytic reasoning (Kahneman and Frederick, 2002; Whittaker, 2018), whilst RPD highlights that anomalous situations require a deliberate sensemaking process to bring about a suitable pattern-match (Klein et al, 2007). For Klein et al (2007), this more deliberate process of checking and revising is also a form of sensemaking. Social workers tend to use slower, more analytic reasoning when faced with particularly novel, complex or high-risk cases (Hackett and Taylor, 2014). The interplay between system 1 and system 2 thinking also explains how intuition can be developed to promote the quick, skilled decision-making that has been observed in experienced social workers undertaking assessments of children (Leonard and O'Connor, 2018; Whittaker, 2018).

\section{How intuitive sensemaking can distort judgement}

If sensemaking is viewed as an intuitive process that operates through heuristic shortcuts or patternmatching, one issue is that it can be prone to bias. The HB tradition highlights the propensity for human error when forming intuitive judgements (Kahneman and Klein, 2009) and child and family social workers may be prone to bias when relying on intuition (Munro, 1999).

Confirmation bias, for instance, leads social workers to favour evidence that confirms an existing hypothesis and reject or minimise disconfirming evidence. Confirmation bias has been identified as a pervasive problem within social work assessment (Kirkman and Melrose, 2014; Munro, 1999; Taylor, 2017). Imagine, for instance, a scenario where a social worker who is undertaking an assessment of a family where there are concerns around neglect. On the first two visits the home has appeared tidy and the children have seemed clean and well-cared-for. On the third visit, however, the children are dirty and the house is unsanitary. The mother explains that the children have been playing outside and she is behind with the housework after a busy week. How the social worker interprets the home conditions, the children's presentation and the mother's explanation may be influenced by an existing hypothesis about the family. If the social worker has come to the view that the children's care is 'good enough', they might interpret the mother's account uncritically, and fail to consider an alternative hypothesis, for example that the final visit could be more representative of everyday life for the family than the earlier visits.

Where intuition is relied upon uncritically there is a risk that alternative hypotheses may be excluded and initial impressions may persist even in the face of seemingly contrary evidence (Munro, 1995). For instance, where a social worker perceives a parent to be 'closed' or 'uncooperative' during an initial meeting, there is the risk that they will continue to assume that the parent is withholding information or will not engage with support offered to them (Cook, 2017). In this way, intuitive sensemaking may lead to bias. To mitigate the risk of bias, the HB and FFH traditions, propose the use of heuristic tools, such as decision trees, that are based upon established knowledge relating to typical decision-making scenarios (Kirkman and Melrose, 2014; Taylor, 2017). Such tools help to avoid the pitfall of missing pertinent information, whilst also acting as a check against individual unconscious bias (Kirkman and Melrose, 2014; Taylor, 2017) of the types described above. Reflection upon how decisions are made and opportunities for case consultation to discuss hypotheses, for example through reflective 
supervision, can act as further safeguards against the impact of bias (Munro, 2011; Kirkman and Melrose, 2014).

This section has outlined how sensemaking can be viewed as intuitive process. Viewing sensemaking in this way allows us to conceptualise how social workers move from the data available - which is often indeterminate and complex, to form an initial hypothesis. However, this intrapersonal focus does not address the important interpersonal and social aspects of sensemaking in a child and family social work context. The way in which social workers make sense of their experiences to formulate judgements cannot be separated from the wider context in which such processing takes place (Helm and Roesch-Marsh, 2017) and the emotional and sensory aspects of sensemaking (Ferguson, 2018). The next two ways of conceiving sensemaking address these aspects of assessment.

\section{Sensemaking as social storytelling}

A different way of conceptualising sensemaking in child and family social work is to view it as a process of social storytelling. In social work assessment, the process through which a judgement is formed can be conceived of as a process of constructing a narrative account. As White and Stancombe (2003: 20) observe: "judgement[s] are 'storied'. Professionals 'take the history', then retell it in a form consistent with their specialist knowledge". The notion of sensemaking as a form of narrative or storytelling has its roots in organisational studies. For instance Weick (2011) argues that sensemaking creates order and this is achieved through the construction of a narrative about an event that renders it explicable (Weick et al, 2005; Weick, 2011). Sensemaking is the process of formulating a story based on situational cues; fragments of information are selected, and interpreted to formulate a cohesive story that has explanatory power (Weick et al, 2005) and can convey meaning to others. For instance, writing about assessment work, De Montingy (1995: 111) states:

I had to learn how to read the signs ... to tell stories about neglect and abuse. I and other social workers collected the signs to make cases. Our collection of signs from daily life became the basis for legitimising our interventions into clients' lives.

Most of these 'signs' were seen within the family homes, the contents of bedroom and the kitchens in flats and houses. These signs then need to be translated into a coherent narrative of family life in order to generate an assessment.

Sensemaking conceived of in this way is an inherently social process; story-building is often collaborative and aimed at creating shared understanding between individuals in the context of their organisation (Weick, 2011). As de Montingy (1995) suggests - one tells a story to 'make cases'. Sensemaking when undertaking assessment in a child and family social work context is a shared process; it involves political and organisational discourse, talk within teams, and shared thinking in meetings and supervision. For this reason, sensemaking in child welfare investigation is characterised by Avby (2015: 95) as a process of 'social rationalization'. Multi-agency working provides opportunities for shared understanding via a process of "talking it through" (Roesch-Marsh, 2018: 410), whilst social work teams provide further opportunities for sensemaking through challenge and exploring safe uncertainty (Helm, 2017). Biggart et al (2017: 123) similarly found that "discussing cases with colleagues and supervisors helped [child and family social workers] create more coherent narratives about their cases".

Ecological understandings of how judgements are made emphasise that the process involves interaction between the individual social worker, the team, organisation, and wider social context (Helm and Roesch-Marsh, 2017). The idea of sensemaking as social storytelling enables us to understand how social workers select, process, and interpret assessment information through talk and telling. The way a case is framed in initial conversations with colleagues offers insight into the way the case is beginning to be formulated by the social worker (Helm, 2013). Social work colleagues then 
act as a sounding board for exploring different conceptualisations of a case (Helm, 2017), whilst supervisors, colleagues and other professionals offer opportunities for further sensemaking and narrative-building (Biggart et al, 2017; Roesch-Marsh, 2018). This enables a judgement to be reached in the process of completing an assessment: a story is built via a sensemaking process until it has coherence and can inform action.

For example, an experienced duty social worker undertakes an assessment visit to a child at school following a report that the child has a number of small bruises on their arm. The social worker reviews the referral information and prior case history and sees a previous child protection investigation due to a potential non-accidental injury to an older sibling. She visits the child at school and then the mother at home. The child seems wary and the mother gives a contradictory account of how the child sustained the bruises. The social worker speaks to her supervisor and they conclude that it is likely the bruises were caused non-accidentally. In this example, the way the cues from the referral information and encounters with the child and mother are interpreted is likely to be influenced by the social worker's specialist knowledge (White and Stancombe, 2003). The social worker talks the case through with their supervisor to pull together the various fragments of the story into a coherent narrative. The narrative that the child is a potential victim of physical abuse does not come about in isolation, but rather through the interaction of personal, professional, organisational, and societal influences on how information is selected, interpreted and used in the sensemaking process (Weick et al, 2005; Helm and Roesch-Marsh, 2017).

\section{How the process of social storytelling can distort sensemaking}

Dominant societal narratives can influence how stories are told. This in turn has the potential to negatively influence sensemaking. For instance, dominant narratives about children as rights-bearing, vulnerable individuals can lead to professional accounts that decontextualise the child from their family (Collings and Davies, 2008) and promote stories about parents that characterise them as a source of risk rather than as themselves victims of poverty or marginalisation

Social work teams can either facilitate or inhibit the sensemaking process. Where team cultures do not promote challenge, opportunities for reflective and collaborative sensemaking are more limited (Helm, 2017). Saltiel (2016) observed that decisions about whether cases were accepted by a duty team were influenced by team resources and workload; team-level conceptions about threshold may influence how social workers make sense of information to inform decisions. Social work teams may also create narratives that conceptualise other professionals, agencies and children and families in a negative way. Such talk "function[s] as a way of asserting the team's identity and their assumption of collegial competence" (Saltiel, 2016: 2110) but potentially excludes alternative constructions that challenge or threaten dominant narratives within the team.

A further difficulty is the multiplicity of possible narratives and their inherently fractured nature. This difficulty is summarised by van de Luitgaarden (2011: 26-27):

behaviour that could be labelled as "child abuse" is.....constructed on the basis of narrative accounts provided by service users and involved professionals...... these narratives are often incomplete, ambiguous or contradictory, or may not exist at all.

The wide range of possible stories about a case, coupled with issues in establishing the veracity of any one narrative, can lead to a position of relativism. Social workers' responses to the challenges of such relativism can also be problematic. Roets et al (2017) found that when student social workers sought to tell the 'true' story in respect of risk to a child, they made inferences that were not well-founded in the information presented. Roets et al (2017) argue for adopting a 'storytelling' approach that is open to revision, dialogue and multiple perspectives. Reflective group discussions are one means of 
ensuring such an approach is maintained (Roets et al, 2017), supporting the notion that sensemaking is a social, dialogic process.

Whilst conceiving of sensemaking as a form of social storytelling enables the social and interpersonal dimensions of sensemaking to be brought to the fore, the intrapersonal processes of sensemaking are less fully explored. Weick et al (2005) acknowledge that the interplay of emotion and sensemaking is an area insufficiently explored within the storytelling approach.

\section{Sensemaking as an emotionally-informed process}

Assessing risk to children and making decisions that impact on their lives is inherently emotive work (Morrison, 2007). Within the field of psychology, the role that affect plays in judgement is acknowledged (see Finucane et al, 2003; Topolinski, 2011). However, affect is defined as a relatively simplistic positive or negative unconscious response to situational cues, and therefore differs from the more complex and sophisticated language of emotion (Finucane et al, 2003). The role that emotion plays is less well-explored and attempts to understand the interplay between emotion, cognition and judgement are more provisional.

The notion of sensemaking as an emotionally-informed process is therefore yet to be fully theorised; intuitive and social storytelling perspectives on sensemaking largely exclude the role of emotions and unconscious responses (Weick et al, 2005; Klein et al, 2007). However, recent empirical research in the field of child and family social work has shed light on the role that emotion can play in assessing risk to children and families (Forsberg and Vagli, 2006; Cook, 2017; Lees, 2017; Turney and Ruch, 2018) and enables us to begin to understand sensemaking as an emotional as well as cognitive process. For instance, Cook (2017) found that social workers' emotional responses informed how they made sense of risk during initial assessment visits. Emotional responses can act as a triggers for social workers to probe further, and initial 'gut feelings' experienced by social workers can sensitise workers to possible indicators of risk (Cook, 2017). Emotional interactions with parents are also important sources of information during home visits, with social workers' perceptions of parents' emotional congruence being correlated with their perception of the level of risk to the child (Cook, 2017). Lees (2017) found that assessment in social work involves both emotion and cognition. Emotional information can help social workers to make sense of their encounters with families, whilst cognitive processes help to render the emotion information intelligible (Lees, 2017). The way in which emotional responses are framed in social workers' talk can also have a significant impact on how decisions are made. Sensemaking conversations are often initiated using emotional frames; Helm (2013: 29-30) found that workers would often begin sensemaking conversations with colleagues using frames such as "This one is really worrying..." or "I feel so guilty...". Forsberg and Vagli (2006) found that the ability of workers to continue to hold and acknowledge difficult feelings in conversation with others enabled them to consideration of a wider range of responses when decisions needed to be made.

Research on alternative supervision models and the use of work discussion groups has suggested that emotion plays a crucial role in sensemaking discussions. The consideration of emotion information alongside event information in supervision enables deeper thinking and greater consideration of alternative perspectives and hypotheses (Turney and Ruch, 2018). Similarly, the opportunity to safely explore emotional responses within work discussion groups has the potential to deepen and enrich workers' understanding of children and families (O'Sullivan, 2018).

Emotion information, which consists of the social worker's own emotional responses to an encounter alongside a recognition of others' emotional presentation, tends to be tentative and provisional. Sensemaking in this context is the process through which emotion information is translated into language. It is the way that immediate gut feelings are reflected upon and have significance attached to them (Cook, 2017) to create an account that can be understood by others (Lees, 2017). 


\section{How emotions can distort sensemaking}

Social workers' initial affective responses when undertaking assessment visits can colour the way in which they perceive risk. Parental openness, the coherence of the account given, and the parent's emotional congruence tend to be correlated with more optimistic judgements about risk to children (Hackett and Taylor, 2014; Cook, 2017). This may be evidence of the affect heuristic at play (Finucane et al, 2003), whereby positive or negative gut feelings can influence perceptions of risk and lead to bias. Social workers therefore need to be mindful that their initial emotional response to a situation needs to be reflected upon and tested to help minimise the kind of bias that can be induced by affective responses (Cook, 2017; Lees, 2017)

The emotionally-demanding nature of assessing risk to children creates further complications for sensemaking. Social workers unconsciously deploy psychological defences when threats, such as overwhelming emotional states, are present (Ferguson, 2018). These defences can block social workers' ability to think clearly; when their focus becomes survival of the self against the perceived threat, they retreat to a safe psychological and emotional distance (Cooper, 2005; Ferguson, 2018; O'Sullivan, 2018). This retreat keeps the social worker psychologically safe but inhibits their capacity to make sense of what they see and hear. This kind of response to overwhelming anxiety helps to account for how professionals "both saw and did not see what was in front of their eyes" (Cooper, 2005: 8) in the Victoria Climbié case.

The propensity of emotional states to overwhelm cognition runs the risk of disrupting sensemaking. Emotional disequilibrium can impair cognition and problem-solving skills (Rimé, 2009) and for emotion information to be most useful it needs to be considered and understood at both emotional and cognitive levels (Lees, 2017). The current context of child and family social work, with its focus on risk and accountability, may not necessarily promote the kind of safe emotional space that is required to strike the necessary balance between emotion and cognition (O'Sullivan, 2018; Turney and Ruch, 2018).

Emotionally-informed perspectives on sensemaking suggest that emotions can act as a risk or as a resource for professional judgement. Such perspectives are, however, relatively underdeveloped and further research is needed to ascertain how social workers use their emotional responses to inform their assessments.

\section{Discussion: A psychosocial model of sensemaking}

This article has shed light on the "largely invisible, taken-for-granted social process" (Weick et al, 2005: 417) of sensemaking, which underpins assessment and decision-making in child and family social work. The three lenses considered above highlight the intrapersonal, interpersonal, and social dimensions of the sensemaking process. It is this combination of the individual, relational and social that leads us to conceptualise sensemaking as a psychosocial process. The three lenses considered here share some key features, particularly the notion that sensemaking operates to render experiences and information intelligible. For instance, within the intuitive tradition, pattern-matching (Klein, 2015) and the use of heuristics (Taylor, 2017) explain how individuals quickly make complex data comprehensible. Sensemaking as social storytelling involves the ordering of events and making them explicable (Weick et al, 2005). Emotionally-informed approaches to sensemaking highlight that for emotion information to be useful, it needs to be 'translated' into a form that can be understood (Lees, 2017

Taken individually, the different lenses for understanding the sensemaking process do not adequately account for the unique psychosocial environment (Taylor, 2017) in which social workers undertake assessments of children and their families. However, when combined the three lenses 
provide a picture of sensemaking as a psychosocial process involving intrapersonal, social and emotional processes. Our conceptualisation of sensemaking as a psychosocial process draws together the unifying threads of the three lenses and leads to six propositions about sensemaking. The first proposition unites a key feature of all three lenses. Propositions two and three relate primarily to intuitive understandings of sensemaking. Propositions four and five relate to the idea of sensemaking as social storytelling. Proposition six relates to sensemaking understood as an emotionally-informed process.

1. Sensemaking is a process of formulation. We use 'formulation' to highlight the provisional nature of sensemaking and the way that it operates in the liminal space between experience and judgement. Story fragments are worked up towards a coherent narrative (Weick et al, 2005), in the formulation of an initial impression or gut feeling on a home visit (Cook, 2017), and in framing a discussion with a colleague to elicit sensemaking conversation (Helm, 2013).

2. Sensemaking involves movement between conscious and non-conscious processes. This is evident in the literature from the psychology of decision-making, both from the HB tradition and the NDM tradition. Whilst sensemaking is often intuitive, more deliberate sensemaking takes place when complex or anomalous situations are experienced. Empirical research evidences the ways in which social workers utilise both intuitive and analytic reasoning when assessing children, often moving between the two (Hackett and Taylor, 2014; Whittaker, 2018).

3. Sensemaking can be developed through experience and learning through reflection. Kahneman and Klein (2009) argue that expertise is developed through repeated exposure to decision-making environments and through learning from decisions made. Conscious reflection upon how decisions are reached can help to develop intuitive sensemaking and mitigate the risk of bias (Kirkman and Melrose, 2014). Empirical research on social work decision-making supports the notion that expertise can be developed in this way; experienced social workers are more adept at quickly identifying and responding to pertinent situational cues when making assessment decisions (Leonard and O'Connor, 2018; Whittaker, 2018).

4. Sensemaking is inseparable from the environment in which it takes place. Weick et al (2005) highlight that social systems interact with, and influence, the sensemaking process. Sensemaking is influenced by wider, dominant narratives about childhood and social work Collings and Davies, 2008; Parton, 2011) as well as the team an organisational environments in which sensemaking takes place (Helm, 2017; Roesch-Marsh, 2018).

5. Sensemaking is a dialogic process. Klein et al (2007) and Weick et al (2005) support the notion of sensemaking involving building a coherent account that can be expressed in language. Cook (2017) found that part of the sensemaking process involved social workers' seeking to articulate their initial implicit impressions, either through a process of self-reflection or dialogue with another. Helm $(2013,2017)$ and Roesch-Marsh (2018) identified that colleagues and supervisors play a role in enabling sensemaking through dialogue.

6. Sensemaking is an emotionally-informed as well as cognitive process. Emotion states provide cues that are part of the sensemaking process (Cook, 2017) and emotion information can make an important contribution to undertaking assessments of children (Lees, 2017). Where social workers explore emotional responses, a wider range of alternative hypotheses tend to be considered (Forsberg and Vagli, 2006; O'Sullivan, 2018; Turney and Ruch, 2018). On the other hand, overwhelming emotional states can disrupt or block sensemaking (Rimé, 2009; Ferguson, 2018). 


\section{Implications}

This article has conceptualised sensemaking in child and family social work as a psychosocial process, combining intuition, social storytelling and emotion. As well as advancing our theoretical understanding of sensemaking in social work, this conceptualisation has practical implications for workers undertaking assessments and organisations responsible for the training and support of social workers.

In the time-limited and indeterminate context of risk assessment, intuition plays a vital role in the way that social workers make sense of risk. A working knowledge of the 'predictable biases' associated with intuitive reasoning (such as confirmation bias) may help social workers and their supervisors to adopt a critical perspective on their sensemaking processes, particularly in relation to early assessment where the risk of confirmation bias is high. In the context of rapid risk assessment, workers require spaces and opportunities to bring system 2 thinking (analysis) to bear on system 1 thinking (intuition). Aside from seeking to minimise error, there is also a need within social work organisations to support the development of effective intuition. If, as the research suggests, expertise is developed through accumulated experience and subsequent pattern recognition, social workers require the opportunity to reflect back on their initial intuitive responses once a case has been concluded and support to articulate and identify the patterns within their assessment experience. For this to happen, organisations must ensure that there are 'feedback loops' (Kirkman and Melrose, 2014) in place to promote learning - particularly in assessment teams where workers have no further contact with the case following initial assessment.

Viewing sensemaking as a process of social storytelling emphasises the need to recognise the impact of the decision-making 'ecology' (Saltiel and Lakey, 2019; Helm and Roesch-Marsh, 2017) on the way that social workers make sense of their cases. For social workers, recognising the extent to which one's team or organisation employs a 'risk frame' towards parents may help social workers to adopt a critically reflective stance in relation to their assessment work (Cook, 2019). Since sensemaking is a dialogic and social process, social work organisations must seek to maximise spaces where informal support and team talk can occur. Consideration must be given to the impact of hot-desking, remote working or other agile working practices (see Jeyasingham, 2016) which may reduce these possibilities.

Considering sensemaking as an emotionally-informed, as well as cognitive, process emphasises the need for organisations to provide supervisory support which addresses both of these aspects of assessment. The Cognitive and Affective Supervisory Approach (CASA) (Turney and Ruch, 2018) is one possible tool for this purpose. For emotion information to be helpful, rather than distort or even shut down sensemaking, social workers need support to process their responses and consider the impact of emotion on their reasoning. 


\section{References}

Avby, G. (2015) Professional practice as processes of muddling through: a study of learning and sensemaking in social work. Vocations and Learning, 8, 1, 95-113.

Biggart, L., Ward, E., Cook, L. and Schofield, G. (2017) 'The team as a secure base: promoting resilience and competence in child and family social work', Children and Youth Services Review, 83, 119-130.

Broadhurst, K., Wastell, D., White, S., Hall, C., Peckover, S., Thompson, K., Pithouse, A. and Davey, D. (2010) 'Performing 'initial assessment': identifying the latent conditions for error at the front-door of local authority children's services', British Journal of Social Work, 40, 352-370.

Buckley, H. (1999) 'Child protection practice: an ungovernable enterprise?' The Economic and Social Review, 30:1, 21-40.

Collings, S. and Davies, L. (2008) "For the sake of the children': making sense of children and childhood in the context of child protection', Journal of Social Work Practice, 22:2, 181-193.

Cook, L. (2016) 'Professional judgement in social work: making sense of the initial home visit', University of East Anglia, PhD thesis.

Cook, L. (2017) 'Making sense of the initial home visit: the role of intuition in child and family social workers' assessments of risk', Journal of Social Work Practice, 31:4, 431-444.

Cook, L. (2019) Storytelling among child welfare workers: constructing professional role and resilience through team talk. Qualitative Social Work (Accepted, in press)

Cooper, A. (2005) 'Surface and depth in the Victoria Climbié inquiry report', Child and Family Social Work, 10, 1-9.

de Montingy, G. (1995) Social Working: An Ethnography of Frontline Practice. Toronto and London: University of Toronto press.

de Montigny, G. (2018) 'Social workers' peculiar contribution to ethnographic research', Qualitative Social Work, 17:3, 452-468.

Ferguson, H. (2018) 'How social workers reflect in action and when and why they don't: the possibilities and limits to reflective practice in social work, Social Work Education, DOI:

10.1080/02615479.2017.1413083.

Finucane, M. L., Peters, E. and Slavik, P. (2003) 'Judgment and decision making: The dance of affect and reason', in Schneider S. and Shanteau, J. (Eds.), Emerging Perspectives on Judgment and Decision Research, Cambridge: Cambridge University Press.

Forsberg, H. and Vagli, A. (2006) 'The social construction of emotions in child protection case talk', Qualitative Social Work, 5:1, 9-31.

Hackett, S. and Taylor, A. (2014) 'Decision-making in social work with children and families: the use of experiential and analytical cognitive processes, British Journal of Social Work, 44, 2182-2199. 
Helm, D. (2013) 'Sense-making in a social work office: an ethnographic study of safeguarding judgements', Child and Family Social Work, 21:1, 26-35.

Helm, D. (2017) 'Can I have a word? Social worker interaction and sense-making', Child Abuse Review, 26, 388-398.

Helm, D. and Roesch-Marsh, A. (2017) 'The Ecology of Judgement: A Model for Understanding and Improving Social Work Judgements', British Journal of Social Work, 0, 1-16.

Jeyasingham, D. (2016) 'Open spaces, supple bodies? Considering the impact of agile working on social work office practices. Child and Family Social Work, 21, 209-217.

Kahneman, D. and Frederick, S. (2002) 'Representativeness revisited: Attribute substitution in intuitive judgment', in Gilovich, T., Griffin, D. and Kahneman, D. (Eds.), Heuristics and Biases: The Psychology of Intuitive Judgment, Cambridge: Cambridge University Press.

Kahneman, D., and Klein, G. (2009) 'Conditions for intuitive expertise: a failure to disagree', American Psychologist, 64, 515-526.

Kirkman, E. and Melrose, K. (2014) Decision-making in children's social work: An analysis of the 'front door' system, London: Department for Education.

Klein, G. (2015) 'A naturalistic decision making perspective on studying intuitive decision-making', Journal of Applied Research in Memory and Cognition, 4, 164-168.

Klein, G., Philips, J. K., Rall, E. L. \& Peluso, D. A. (2007) 'A data-frame theory of sensemaking', in Hoffman, R. R. (Ed.) (2007) Expertise Out of Context: Proceedings of the Sixth International Conference on Naturalistic Decision Making, New York: Lawrence Erlbaum Associates, p.113-155.

Laming, H. (2003) The Victoria Climbié Inquiry Report, London: The Stationery Office.

Laming, H. (2009) The Protection of Children in England: A Progress Report, London: The Stationery Office.

Lees, A. (2017) 'Facts with feelings: social workers' experiences of sharing information across team and agency borders to safeguard children', Child and Family Social Work, 22, 892-903.

Leonard, K. and O'Connor, L. (2018) 'Transitioning from "outside observer" to "inside player" in social work: practitioner and student perspectives on developing expertise in decision-making', Journal of Social Work Practice, 32:2, 205-218.

Morrison, T. (2007) 'Emotional intelligence, emotion and social work: context, characteristics, complications and contribution', British Journal of Social Work, 37, 245-263.

Munro, E. (1995) 'The power of first impressions', Practice, 7:3, 59-65.

Munro, E. (1999) 'Common errors of reasoning in child protection work', Child Abuse and Neglect, 23:8, 745-758. 
Munro, E. (2008) Improving reasoning in supervision. Social Work Now, 40, 6, 3-9. Munro, E. (2011) The Munro Review of Child Protection: Final Report, a Child-Centred System, London: The Stationery Office.

O'Sullivan, N. (2018) 'Creating space to think and feel in child protection social work; a psychodynamic intervention', Journal of Social Work Practice, 1-10.

https://doi.org/10.1080/02650533.2018.1460589.

Parton, N. (2011) 'Child protection and safeguarding in England: changing and competing conception of risk and their implications for social work', British Journal of Social Work, 41, 854-875.

Platt, D. and Turney, D. (2014) 'Making threshold decisions in child protection: a conceptual analysis', British Journal of Social Work, 44, 1472-1490.

Rimé, B. (2009) 'Emotion elicits the social sharing of emotion: theory and empirical review', Emotion Review, 1:1, 60-85.

Roesch-Marsh, A. (2018) 'Professional relationships and decision-making in social work: lessons from a Scottish case study of secure accommodation decision making', Qualitative Social Work, 17:3, 405422.

Roets, G., Roose, R., De Wilde, L. and Vanobbergen, B. (2017) 'Framing the "child at risk" in social work reports: truth-telling or storytelling?', Journal of Social Work, 17:4, 453-469.

Saltiel, D. (2016) 'Observing front line decision making in child protection', British Journal of Social Work, 46, 2104-2119.

Saltiel, D. and Lakey, R. (2019) 'Analysing invisibility: the decision-making ecology and home visits', Child \& Family Social Work, p.1-8. (DOI: 10.1111/cfs.12649).

Taylor, B. (2017) 'Heuristics in professional judgement: a psycho-social rationality model', British Journal of Social Work, 47, 1043-1060.

Topolinski, S. (2011) 'A process model of intuition', European Review of Social Psychology, 22:1, 274315.

Turney, D. and Ruch, G. (2018) 'What makes it so hard to look and listen? Exploring the use of the cognitive and affective supervisory approach with children's social work managers', Journal of Social Work Practice, 32:2, 125-138.

van de Luitgaarden, G. (2009) 'Evidence-based practice in social work: lessons from judgement and decision-making theory', British Journal of Social Work, 39, 243-260.

van de Luitgaarden, G. (2011) 'Contextualizing judgements and decisions in child protection practice at the point of first referral', Journal of Social Intervention: Theory and Practice, 20:3, 24-40.

Weick, K. E. (2011) 'Organized sensemaking: a commentary on process of interpretive work', Human Relations, 65:1, 141-153.

Weick, K. E., Sutcliffe, K. M. and Obstfeld, D. (2005) 'Organizing and the process of sensemaking', Organization Science, 16:4, 409-421. 
White, S. J. and Stancombe, J. (2003) Clinical Judgement in the Health and Welfare Professions: Extending the Evidence Base, London: Open University Press.

Whittaker, A. (2018) 'How do child-protection practitioners make decisions in real-life situations? Lessons from the psychology of decision-making', British Journal of Social Work, 0, 1-18. 